\title{
COMPARATIVE ASSESSMENT OF DISCRETE ELEMENT METHODS AND COMPUTATIONAL FLUID DYNAMICS FOR ENERGY ESTIMATION OF THE CULTIVATOR WORKING BODIES
}

\author{
Salavat Mudarisov*, Ildar Farkhutdinov, Raushan Aminov, Zinnur Rakhimov, Rustam Bagautdinov, \\ Ildar Rakhimov, Ilshat Gainullin \\ Bashkir State Agrarian University, Ufa, Russian Federation
}

Computer modeling of various technological processes, including soil treatment, has currently become an urgent task. The purpose of the study is to make energy evaluation of the tilling implement working tool by modeling the technological process with the use of discrete element methods and the method of computational fluid dynamics. The obtained results were compared with the results of real experiments. The paper presents the results of the comparative energy assessment of the cultivator's working tool. The results were obtained during real experiments conducted in the tillage bin by modeling the soil treatment technological process with the use of discrete elements (DEM) and computational fluid dynamics methods (CFD). To measure the working tool tractive resistance in the tillage bin an experimental unit with strain indicators of $5000 \mathrm{~N}$ rating value was created. The unit has the function of possible technological and structural adjustments. Soil particles configurations were selected by modeling the technological process with the use of the discrete elements method. Literature sources and data of various soil examinations were used to determine physical and mechanical properties of soil. Such values as Poisson's ratio $(V)$, static friction coefficient ( $f$ ), shear modulus (G), and Young's modulus (E) were set. According to the results the values got using computational fluid dynamics method are similar to the results of real experiments conducted in the tillage bin. When using discrete element modeling the value of the instrument tractive resistance is close to real data at low operating speeds.

Key words: discrete elements method, method of computational fluid dynamics, modeling, soil treatment, tractive resistance

\section{INTRODUCTION}

Many technological operations are used to cultivate agricultural crops among which soil treatment operations require greatest energy input. Even with the introduction of new energy-saving technologies of minimum tillage such as No-Till and Strip-Till the interaction of working instruments of cultivators and seeders with the soil is not excluded $[1,2]$. In this regard, when developing new and improving existing working instruments for cultivators and seeders, special attention should be paid to reducing their tractive resistance [3-7].

When developing and improving working bodies of tillage and sowing machines various methods of modeling the soil treatment technological process have been used in recent years. Depending on the ways of numerical implementation of soil treatment models these methods can be divided into three main types: models implemented using the computational fluid dynamics method (CFD) method) [8-11], models designed with the use of the discrete element method (DEM) [12-21] and models developed with the use of finite-element method (FEM method).

Modeling of the soil treatment process implemented with the use of discrete elements method is used rather widely. This method describes well the process of particles movement during their interaction with the working instruments of tillage machines. It can be used to optimize design and technological parameters of working tools.

When modeling the process of soil treatment carried out by a tined cultivator working tool and using discrete elements method the issues of the soil particles interaction are considered [12,22]. Particle properties were selected depending on physical and mechanical features of real soil. The obtained results are equal enough.

The method of discrete elements can be used to study strength characteristics of different soil types $[14,19]$ as well as mixing of soil particles [16].

In addition, some studies [16] prove that when modeling the technological process by using the discrete elements method, physical and mechanical properties of the simulated medium influence the working tool energy performance. The effect of particle size on the tractive resistance of working instruments is studied later [23]. To analyze the results precision, an experimental unit was created. The unit has the function of possible changing the design and technological parameters of the tined cultivator working instrument.

The use of the discrete elements method makes it possible to allocate soil particles of different density and size into layers $[24,25]$. When soil particles are allocated in such a way, the change in soil depth density is taken into account.

Among the disadvantages of the method of discrete elements [13] is impossibility to study both the soil layer de- 
formation caused by the working tool, and the processes of soil loosening and compaction.

According to the study analysis the reliability of the data obtained when using DEM-modeling is largely determined by the correct calibration of physical and mechanical properties of discrete particles and the selected model of their contact, especially when evaluating the working body tractive resistance.

In the work of Karmakar and Kushwaha [8] the CFD method is used to analyze the stress-strain state of the soil layer when it interacts with a narrow vertical working body. In this case, a free surface model was used which made it possible to visualize the process of furrowing after the passage of the working body and the ridge formation in front of it. The correspondence of the modeling results to the real experimental values was observed only when the working body moved at a low speed and a small depth.

In the work of Mudarisov [9] the possibility of using a rheological Newtonian viscous fluid as a soil model was proved. According to further research of Mudarisov et al. [26], the change in pressures, forces and inertia acting on the working bodies of tillage machines largely depend on the viscosity of the simulated medium. For the numerical implementation of the CFD method the Flow Vision program was used. The correspondence between the real soil properties and the viscous liquid of the simulated medium was established later [27].

The possibility of using the CFD method in the study of the interaction between the soil layer and the working surface of the instrument is considered in the work of Zhu et al. [11]. Three-dimensional images of soil pressure distribution on the surface of the working body obtained by the authors were used to assess the wear and durability of the working instrument.
In the work of Peng et al. [15] the existing modeling methods are analyzed. According to the authors, the existing methods do not sufficiently take into account the real properties of soil environment when modeling the soil treatment process. The authors propose to use the Langrangian (smoothed particle method or SPH-method) modeling approach. The paper presents the results of tractive resistance measurements of the working instrument. However, when conducting real experiments, there are no tractive resistance measurements of the same working instruments.

The analysis of the works showed that the correspondence of the results obtained using the DEM and CFD modeling methods to the real soil treatment results obtained during the energy assessment of tillage instruments is largely determined by physical properties of the simulated media. In this regard, this paper presents the results of the evaluation of the working instrument tractive resistance obtained with the use of the method of discrete elements with different coefficient of static friction of particles and their relative positions in comparison with the method of computational fluid dynamics and with the real values of the full-scale experiment in the tillage bin.

\section{THEORY AND EXPERIMENTAL}

The vertical chisel cultivator working instrument used for strip tillage was chosen as a subject for the study.

Real experiments to determine the traction resistance of the working instrument were carried out in the tillage bin of the Department of Agricultural and Technological machines of Bashkir State Agricultural University. A laboratory unit was made for the experiments. The unit was hung on the strain-measuring bogie hinge (Fig. 1).

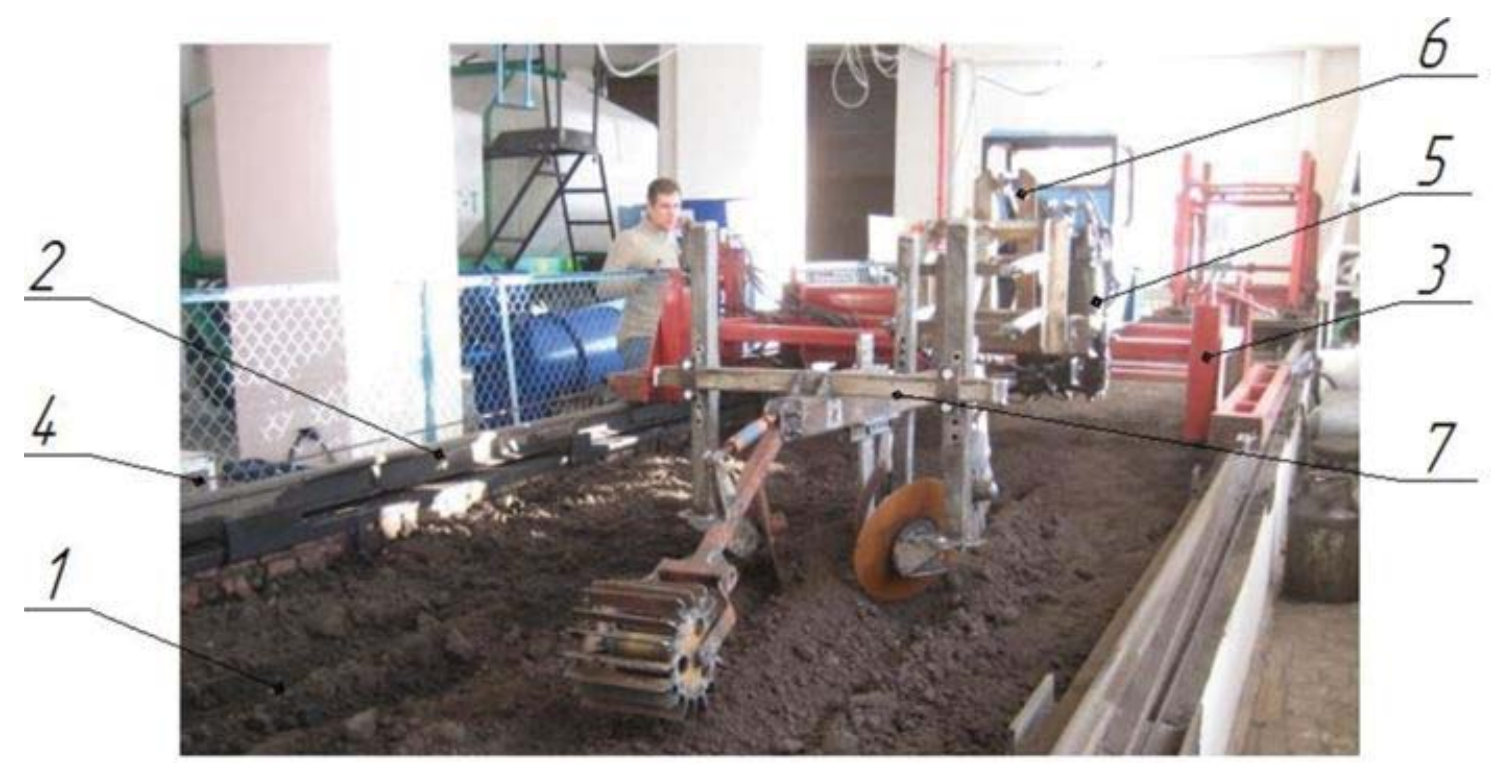

Figure 1: Laboratory unit for determining traction resistance. 1 - tillage bin sized 3x15m; 2 - rails;

3 - powered bogie; 4 - MIC-400D analog to digital converter; 5 - strain-measuring hinge with sensors; 6 - hydraulic system; 7 - developed cultivator gang for strip-till planting 


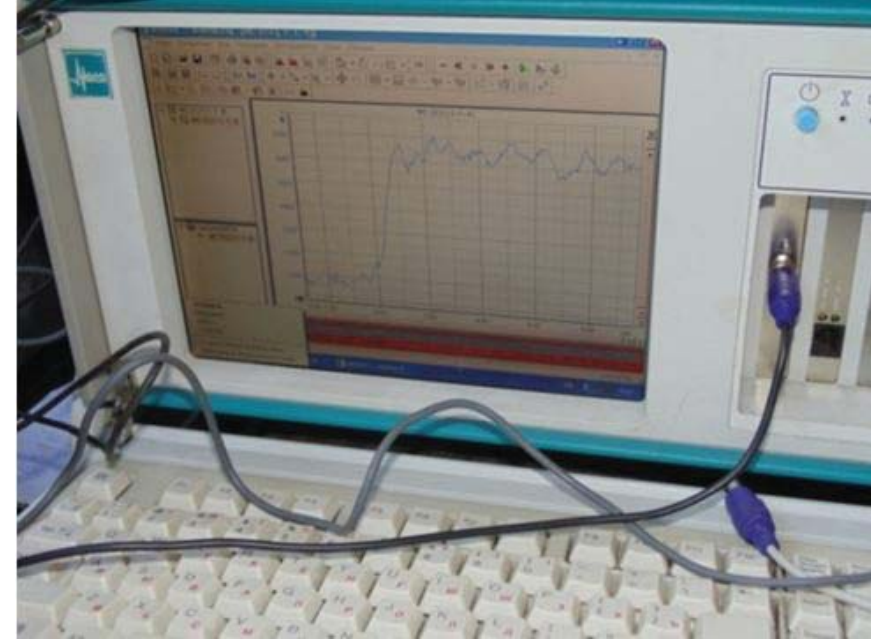

Figure 2: MIC-400D data collection platform

Experimental data were registered and processed data using the MIC-400D data collection platform produced by "Mera" Research and Production Enterprise (Korolev, Russia) (Fig. 2).

A calibrator was used for the equipment calibration (Fig. 3). The tensor link was loaded up with up to 3 tons. GRM20 rupture test machine was used for loading.

Modeling of the soil treatment technological process in the Flow Vision software package was carried out according to the method proposed by Mudarisov $[9,27]$. A free surface model was used for that. The density of the soil medium $\rho=1400 \mathrm{~kg} / \mathrm{m} 3$ was set in accordance with the actual conditions. The viscosity of the soil medium was determined depending on soil particle-size distribution and humidity according to the nomograph of $\mathrm{Mu}$ darisov et al.[27]. If according to the nomograph the humidity of loamy soil $\mathrm{w}=22.5 \%$, then its medium viscosity $v=1000 \mathrm{~N}^{*} \mathrm{~s} / \mathrm{m}^{2}$.

In discrete models soil medium is considered as a system consisting of a number of individual particles. The interaction between particles is based on the laws of contact mechanics.

When using the DEM modeling, particles of the simulated environment can be presented as various combina-

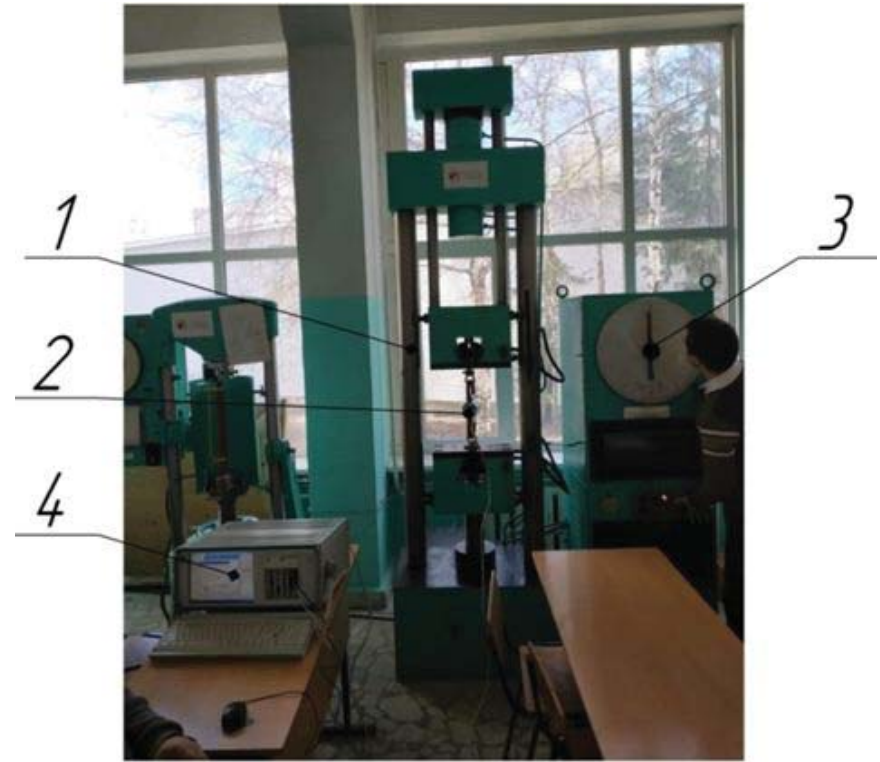

Figure 3: Calibration link. 1 - GRM-20 hydraulic rupture test machine; 2 - tensor link; 3 - mechanical load gage; 4 - MIC-400D data collection platform

tions of balls of different diameters. Typically, in soil modeling, granular particle contacts are realized using the Hertz-Mindlin model [12-14,17]. In addition to determining the number of particles and their relative position, it is necessary to define the conditions of their interaction. Using literary sources $[12-14,17]$ and data from the study of various soils to determine the physical and mechanical properties of soils Poisson's coefficient values $(\mathrm{V}=$ 0.3.0.35), the coefficient of static friction ( $f=0.35 \ldots 0.7)$, the shear modulus $(\mathrm{G}=10 \ldots 12 \mathrm{MPa})$, young's modulus $(E=30 \ldots 35 \mathrm{MPa})$ were set.

We used the following combinations of spherical particles: a single ball, three balls on the apexes of an isosceles triangle, four balls on a single line (Fig. 4). At the same time the diameter of the ball was equal to $1 \mathrm{~mm}$.

The energy indicators of the working instrument in real conditions are also affected by the physical and mechanical soil properties such as its density and humidity. Soil moisture affects the friction of the soil on the working sur-

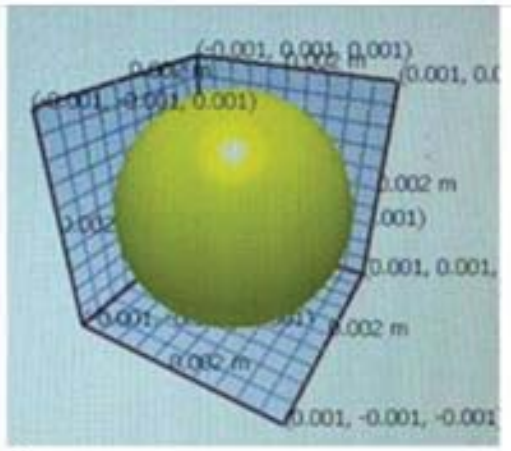

a)

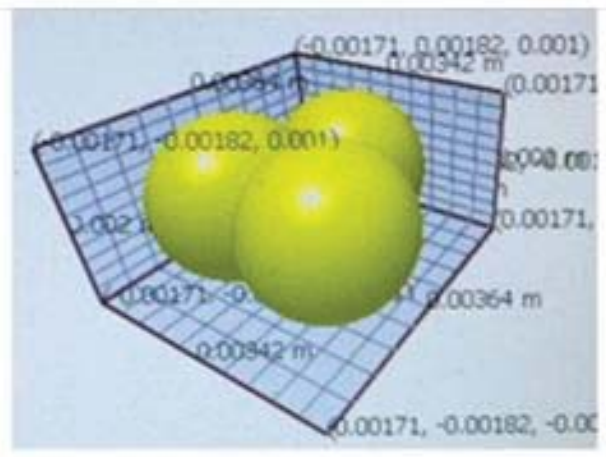

b)

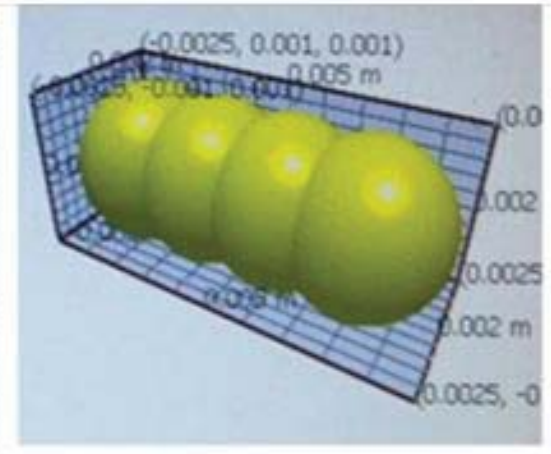

c)

Figure 4: A combination of soil particles for the DEM: a - a single ball; $b-3$ balls on the apexes of an isosceles triangle; $c$ - 4 balls on a single line 
face of the working body and on its tractive resistance. For real experiments carried out in the tillage bin with the use of a working instrument leached black soil of a light - loamy mechanical composition (clay - 17-28\%, sand $67-75 \%, 5-8 \%$ ) was used. During the experiments, the soil was maintained at an average density of $1400 \mathrm{~kg} / \mathrm{m}^{3}$ and a humidity of $\mathrm{w}=22.5 \%$.

\section{RESULTS AND DISCUSSION}

Below are the results of determining the traction resistance of the working tool when modeling CFD and DEM methods, as well as the values of the tractive resistance of the working body on the soil channel at the same speeds.

Table 1 shows the tractive resistance in CFD, DEM simulations for a single ball particle and a real tillage bin experiment. Fig. 5 shows a graphical interpretation of the results.
As can be seen from Fig. 5, the tractive resistance of the working instrument with the CFD method is closer to the real values of real experiments. When using the method of discrete elements it is slightly lower. At the same time the spread of data obtained by DEM-modeling for different values of the static friction coefficient goes up to $20 \%$.

Studies on the influence of the static friction coefficient on the tractive resistance of the working instrument in DEM-modeling is presented in the works of [17,28-30]. The authors found that the most similar results on the tractive resistance were obtained at values of the static friction coefficient in the range of $0.3 \ldots 0.7$. For our soil conditions, the results close to the real values of the tractive resistance were obtained at the static friction coefficient of $f=0.7$.

Table 1: Dependence of the tractive resistance $R$ of the working tool of the cultivator on the speed of movement

\begin{tabular}{|l|c|c|c|c|c|}
\hline \multirow{2}{*}{ Parameters } & \multicolumn{4}{l}{ The movement speed of the working instrument, m/s } \\
\cline { 2 - 6 } & 0.5 & 1 & 1.5 & 2 & 2.5 \\
\hline $\begin{array}{l}\text { Tractive resistance R (DEM, static friction } \\
\text { coefficient f=0.35) }\end{array}$ & 125.8 & 166.8 & 191.5 & 230.5 & 266.8 \\
\hline $\begin{array}{l}\text { Tractive resistance R (DEM, static friction } \\
\text { coefficient f=0.40) }\end{array}$ & 135.1 & 174.8 & 200.9 & 220.5 & 271.1 \\
\hline $\begin{array}{l}\text { Tractive resistance R (DEM, static friction } \\
\text { coefficient f=0.45) }\end{array}$ & 150.1 & 189.5 & 214.7 & 251.3 & 306 \\
\hline $\begin{array}{l}\text { Tractive resistance R (DEM, static friction } \\
\text { coefficient f=0.7) }\end{array}$ & 169.1 & 200.4 & 248.7 & 299.5 & 380 \\
\hline $\begin{array}{l}\text { Tractive resistance R (CFD, medium } \\
\text { viscosity v =1000 N*s / m²) }\end{array}$ & 180.5 & 216.8 & 258.4 & 301.2 & 378.1 \\
\hline $\begin{array}{l}\text { Tractive resistance R on the soil channel } \\
\text { (soil moisture w=22.5\%) }\end{array}$ & 195.4 & 234.6 & 290 & 365.4 & 455.8 \\
\hline
\end{tabular}

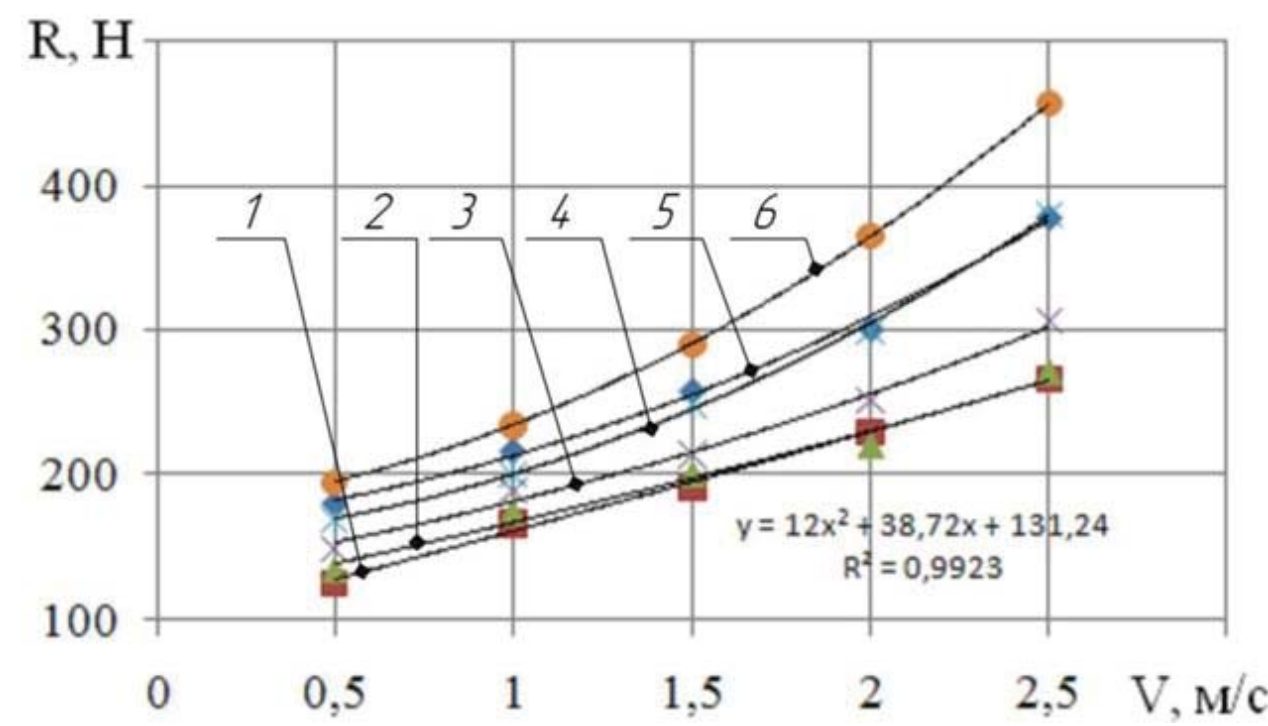

Figure 5: Dependence of the tractive resistance of the cultivator's working instrument on the movement speed. 1 - DEM ( $f=0.35) ; 2$ - DEM ( $f=0.4) ; 3$ - DEM ( $f=0.45) ; 4$ - DEM ( $f=0.7) ; 5$ - CFD-method; 6 - full-scale experiment $(w=22.5 \%)$ 
Table 2 shows the results of DEM modeling for soil particles implemented as three balls on the apexes of an isosceles triangle. Fig. 6 shows a graphical interpretation of the obtained results compared with the CFD modeling and real experiments data.

As can be seen from Fig. 6, the values of the tractive resistance of the working instrument during DEM modeling at low speeds within $0.5 \ldots 1 \mathrm{~m} / \mathrm{s}$ are comparable with the results of real experiments. With a static coefficient $\mathrm{f}=0.7$, the DEM results are close to the results obtained by the CFD method. The spread of the data obtained by DEM at different values of the static friction coefficient is $25 . .35 \%$.

Table 3 shows the results of DEM modeling for soil particles implemented as four balls on a single line. Fig. 7 shows a graphical interpretation of the obtained results compared with the CFD modeling and real experiments data.

As can be seen on Fig. 7, the tractive resistance in DEM modeling is slightly lower compared to the results of real experiments and CFD modeling. At the same time the spread of data obtained by DEM-modeling for different values of the static friction coefficient goes up to $20 \%$.

The dependence of the tractive resistance of the working instrument on the speed of its movement for any modeling methods (Fig 5-7) is approximated using quadratic functions of the form $y=a x^{2}+b x+c$, which does not contradict the laws of agricultural mechanics. The same dependencies of the tractive resistance in the use of DEM-modeling were obtained in the works of Dzyuba et al. [6], Tesliuk et al. [7], Zhu et al. [11], Karmakar et al. [31], and Ani et al. [32].

Table 2: Dependence of the tractive resistance of the cultivator working body on the movement speed (DEM particle - three balls on the apexes of an isosceles triangle)

\begin{tabular}{|l|c|c|c|c|c|}
\hline \multirow{2}{*}{ Parameters } & \multicolumn{5}{c|}{ The movement speed of the working instrument, $\mathrm{m} / \mathrm{s}$} \\
\cline { 2 - 6 } & 0.5 & 1 & 1.5 & 2 & 2.5 \\
\hline $\begin{array}{l}\text { Tractive resistance R (DEM, static friction } \\
\text { coefficient } \mathrm{f}=0.35)\end{array}$ & 145.8 & 172.8 & 201.5 & 225.4 & 280.4 \\
\hline $\begin{array}{l}\text { Tractive resistance R (DEM, static friction } \\
\text { coefficient } \mathrm{f}=0.40)\end{array}$ & 169.5 & 199.1 & 245.1 & 280.8 & 336.5 \\
\hline $\begin{array}{l}\text { Tractive resistance R (DEM, static friction } \\
\text { coefficient f=0.45) }\end{array}$ & 191.2 & 226.4 & 280.1 & 308.4 & 394.2 \\
\hline $\begin{array}{l}\text { Tractive resistance R (DEM, static friction } \\
\text { coefficient } \mathrm{f}=0.7 \text { ) }\end{array}$ & 190.1 & 229.4 & 294.4 & 306.4 & 410.7 \\
\hline $\begin{array}{l}\text { Tractive resistance R (CFD, medium } \\
\text { viscosity v =1000 N*s / m²) }\end{array}$ & 180.5 & 216.8 & 258.4 & 301.2 & 378.1 \\
\hline $\begin{array}{l}\text { Tractive resistance R on the soil channel } \\
\text { (soil moisture w=22.5\%) }\end{array}$ & 195.4 & 234.6 & 290 & 365.4 & 455.8 \\
\hline
\end{tabular}

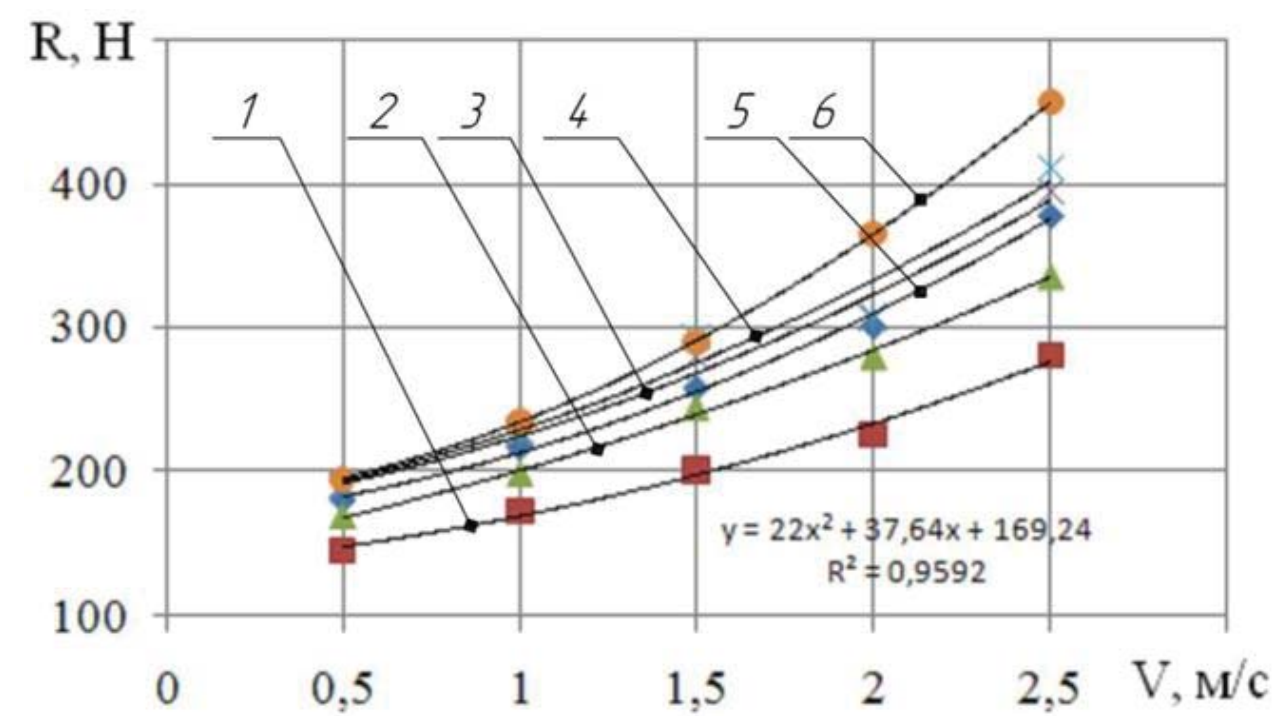

Figure 6: Dependence of the tractive resistance of the cultivator's working body on the speed of movement (DEM particle - three balls on the apexes of an isosceles triangle). 1 - DEM ( $f=0.35) ; 2-D E M(f=0.4)$;

3 - DEM ( $f=0.45) ; 4$ - DEM ( $f=0.7) ; 5$ - CFD-method; 6 - real experiment $(w=22.5 \%)$ 
Theoretical and experimental studies have shown that when the speed of movement increases by $1.5-3.0 \mathrm{~m} / \mathrm{s}$, the tractive resistance of the working instrument increases to $35-40 \%$.
Fig. 8 shows comparative results of visualization of the interaction process between the working instrument and the simulated environment. These results were obtained using the DEM and CFD methods.

Table 3: Dependence of the tractive resistance of the cultivator working body on the movement speed (DEM particle - four balls on a single line)

\begin{tabular}{|l|c|c|c|c|c|}
\hline \multirow{2}{*}{ Parameters } & \multicolumn{5}{|c|}{ The movement speed of the working instrument, $\mathrm{m} / \mathrm{s}$} \\
\cline { 2 - 6 } & 0.5 & 1 & 1.5 & 2 & 2.5 \\
\hline $\begin{array}{l}\text { Tractive resistance R (DEM, static friction } \\
\text { coefficient f=0.35) }\end{array}$ & 99.2 & 123.4 & 141 & 169.4 & 180.7 \\
\hline $\begin{array}{l}\text { Tractive resistance R (DEM, static friction } \\
\text { coefficient f=0.40) }\end{array}$ & 105.4 & 135.1 & 148.2 & 180.7 & 199.8 \\
\hline $\begin{array}{l}\text { Tractive resistance R (DEM, static friction } \\
\text { coefficient f=0.45) }\end{array}$ & 112.4 & 161.1 & 180.1 & 193.2 & 215.3 \\
\hline $\begin{array}{l}\text { Tractive resistance R (DEM, static friction } \\
\text { coefficient f=0.7) }\end{array}$ & 130.2 & 188.4 & 230.5 & 290 & 318.1 \\
\hline $\begin{array}{l}\text { Tractive resistance R (CFD, medium } \\
\text { viscosity v =1000 N*s / m²) }\end{array}$ & 180.5 & 216.8 & 258.4 & 301.2 & 378.1 \\
\hline $\begin{array}{l}\text { Tractive resistance R on the soil channel } \\
\text { (soil moisture w=22.5\%) }\end{array}$ & 195.4 & 234.6 & 290 & 365.4 & 455.8 \\
\hline
\end{tabular}

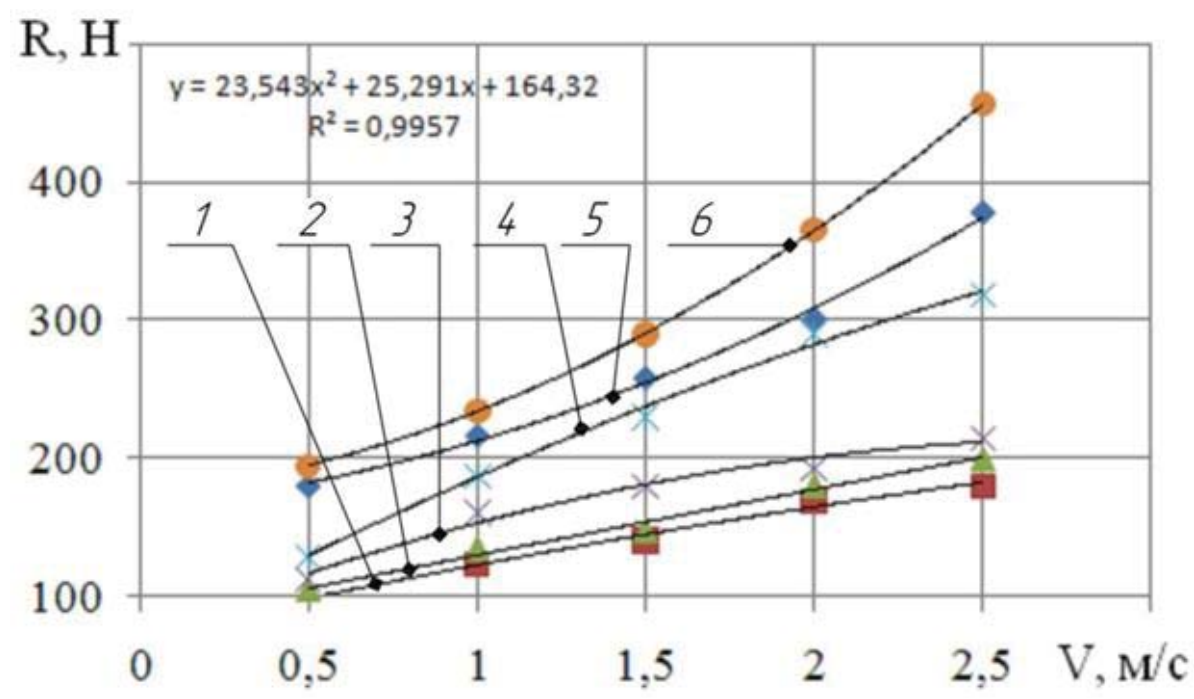

Figure 7: Dependence of the tractive resistance of the cultivator's working body on the movement speed (DEM particle - four balls on a single line). 1 - $D E M(f=0.35) ; 2$ - $D E M(f=0.4) ; 3-D E M(f=0.45) ; 4-D E M(f=0.7)$; 5 - CFD-method; 6 - real experiment $(W=22.5 \%)$

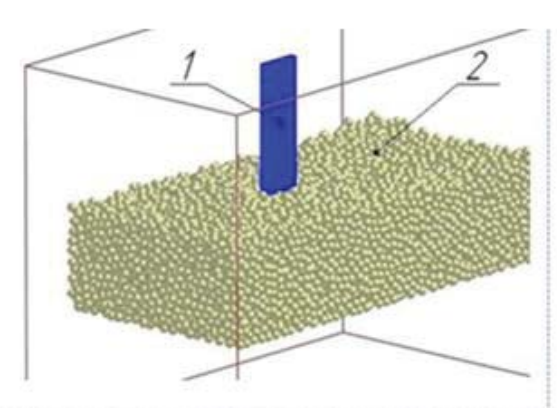

a)

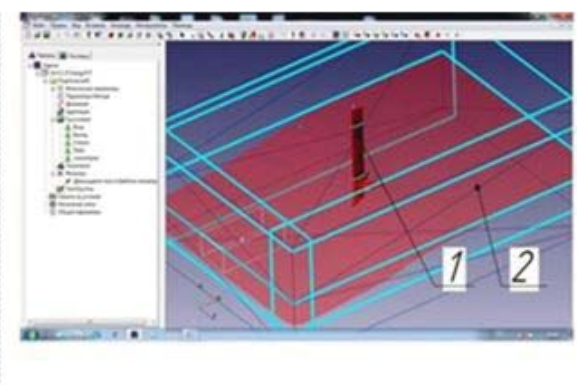

b)

Figure 8: Modeling of the technological process of soil treatment: a) using the method of discrete elements;

b) using the method of computational fluid dynamics. 1 - working body; 2 - soil environment 


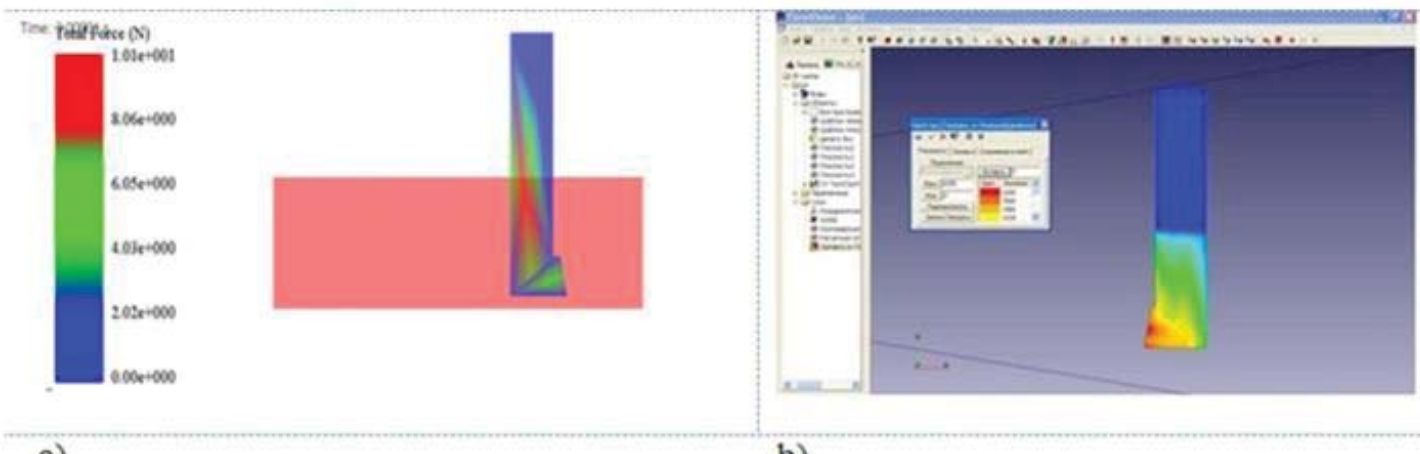

a)

b)

Figure 9: Distribution of soil pressure on the surface of the working instrument, obtained as a result of modeling:

a) using the method of discrete elements; $b$ ) using the method of computational fluid dynamics

Fig. 9 shows the visualization of pressure distribution from the soil environment on the surface of the working instrument, obtained by the methods of discrete elements and computational fluid dynamics. As can be seen from the presented visualization of the soil surface (Fig. 8 ), the process of forming the ridge before the working instrument and the furrow after its passage for DEM is more realistic. This is evidenced by the pressure distribution (Fig. 9) - the zone of contact between the particles and the instrument for DEM extends above the soil surface. When using the CFD method it rises slightly from the surface level of the simulated medium. This is due to the fact that the CFD uses a fluid environment and after interaction with the instrument, it flows to its initial position.

The greatest soil pressure on the surface of the instrument is observed in its lower part.

Similar results on the distribution of soil pressure on the surface of the working instrument during CFD modeling were obtained in the works of Bartzanas et al. [10] and Zhu et al. [11].

The results of the experiments showed that the values of the tractive resistance of the working instrument for loamy soils, which are closest to real values were obtained for the CFD modeling method. In the future for DEM simulations to obtain more accurate results, it is necessary to calibrate soil environment properties on other physical and mechanical properties. For example, on Poisson's ratio $v$, the shear modulus $G$ and elasticity modulus $\mathrm{E}$, since this method gives a more realistic picture on the movement of soil particles during interaction with the working instrument.

\section{CONCLUSIONS}

The results of the experiments showed that the tractive resistance of the working instrument, which was obtained by the method of computational fluid dynamics, is comparable to the results of real experiments in the tillage bin. The tractive resistance of the working instrument during the simulation with the use of discrete elements method is close to the real data at low operating speeds, but is slightly lower (more than $1.5 \mathrm{~m} / \mathrm{s}$ ) at higher operating speeds. The presented results show that with an increase in the speed of the working instrument, the tractive resistance also increases. This does not contradict the laws of agricultural mechanics and the data obtained by researchers earlier.

The application of discrete element methods or computational liquid dynamics depends on the goals set by the researcher. To study the process of mixing soil particles, the method of discrete elements has an advantage, but for studying the stress-strain state of the soil during processing the method of computational hydrodynamics is better.

It has been revealed that the tractive resistance of the working instrument is affected by the configuration and size of soil elements. The results, which are closer to the real results of the tractive resistance for the method of discrete elements, are obtained when used those soil particles which are in the form of three balls located on the apex of an isosceles triangle.

In general, the use of discrete element methods and computational fluid dynamics allow us to assess the quality and energetics of the soil treatment process.

In addition, it should be noted that the discrete elements method is more suitable for the treatment of fine-grained soils such as sandy soils of mechanical texture. When using the dis-crete elements method, more detailed calibration of rheological properties of the model is ne-cessary for a particular soil type.

In the future, in order to obtain adequate values during energetic assessment of soil treatment instruments by using the discrete elements method, it is necessary to study the influence of other rheological properties of the simulated environment - the Poisson's ratio $V$, the shear modulus $\mathrm{G}$, and the elasticity modulus $\mathrm{E}$.

The obtained results and methodology can be used for energetic assessment and optimization of structural and technological parameters of newly created working instruments of tillage tools. 


\section{REFERENCES}

1. Bezverkhova, E.V., Russkiy, V.G. (2010). Resource-saving technologies as the basis for innovative development of crop production. Economy of Agricultural and Processing Enterprises, vol. 9, 4547. (in Russian)

2. Safin, H.M.(2019). Prospects of introduction of notill and strip-till saving technologies in the Republic of Bashkortostan. Rural Patterns,vol. 2, 26-27. (in Russian)

3. Ahmad, F., Weimin, D., Qishud, D., Huimin, F., Hassan, M. (2015). 3-D DEM modeling of single disc furrow opener draft force in no-till paddy soil. International Agricultural Engineering Journal, vol. 24, no. 2, 17-29.

4. Rakhimov, Z., Mudarisov, S., Gabitov, I., Rakhimov, I., Rakhimov, R., Farkhutdinov, I., Tanylbaev, M., Valiullin, I., lamaletdinov, M., Aminov, R. (2018). Mathematical description of the mechanical erosion process in sloping fields. Journal of Engineering and Applied Sciences,vol. 13, no. 8, 6505-6511. DOI:10.36478/jeasci.2018.6505.6511

5. Gabitov, I., Mudarisov, S., Gafurov, I., Ableeva, A., Negovora, A., Davletshin, M., Rakhimov, Z., Khamaletdinov, R., Martynov, V., Yukhin, G.(2018). Evaluation of the efficiency of mechanized technological processes of agricultural production. Journal of Engineering and Applied Sciences,vol. 13,no. 10, 83388345.DOI:10.3923/jeasci.2018.8338.8345

6. Dzyuba, O., Dzyuba, A., Polyakov, A., Volokh, V., Antoshchenkov, R., Mykhailov, A. (2019). Studying the influence of structural-mode parameters on energy efficiency of the plough PLN-3-35. Eastern-European Journal of Enterprise Technologies,vol. 3, no. 1, 55-65.DOI:10.15587/1729-4061.2019.169903

7. Tesliuk, H., Volik, B., Sokol, S., Ponomarenko, N. (2019). Design of working bodies for tillage tools using the methods of bionics. Eastern-European Journal of Enterprise Technologies,vol. 3, no. 1, 49-54. DOI:10.15587/1729-4061.2019.169156

8. Karmakar, S., Kushwaha, R.L. (2005). Simulation of soil deformation around a tillage tool using computational fluid dynamics. Transactions of the ASAE,vol. 48, 923-932.DOI:10.13031/2013.17051

9. Mudarisov, S.G.(2005). Modeling the process of interaction of working bodies with the soil. Tractors and Agricultural Machine,vol. 7, 27-30. (in Russian)

10. Bartzanas, T., Kacira, M., Zhu, H., Karmakar, S., Tamimi, E., Katsoulas, N., Lee I.B., Kittas, C. (2013). Computational fluid dynamics applications to improve crop production systems. Computers and Electronics in Agriculture,vol. 93, 151-167.DOI:10.1016/j. compag.2012.05.012
11. Zhu, L., Ge, J.R., Cheng, X., Peng, S.S., Qi, Y.Y., Zhang, W.F., Zhu, D.Q. (2017). Modeling of share/ soil interaction of a horizontally reversible plow using computational fluid dynamics. Journal of Terramechanics,vol. $\quad 72, \quad 1-8 . \mathrm{DOI}: 10.1016 / \mathrm{j} . j t e r-$ ra.2017.02.004

12. Coetzee, C.J., Els, D.N.J.(2009). Calibration of granular material parameters for DEM modelling and numerical verification by blade-granular material interaction. Journal of Terramechanics,vol. 46, 15-26. DOI:10.1016/j.jterra.2008.12.004

13. Shmulevich, I.(2010). State of the art modeling of soil-tillage interaction using discrete element method. Soil \& Tillage Research,vol. 111, 41-53. DOI:10.1016/j.still.2010.08.003

14. Mak, J., Chen, Y., Sadek, M.A. (2012). Determining parameters of a discrete element model for soil-tool interaction. Soil \& Tillage Research,vol. 118, 117122.DOI:10.1016/j.still.2011.10.019

15. Peng, C., Zhou, M., Wu, W. (2015). Large deformation modeling of soil-machine interaction in clay. In: Papamichos, E., Papanastasiou, P., Pasternak, E., Dyskin, A. (Eds.), Bifurcation and degradation of geomaterials with engineering applications. Proceedings of the 11th International workshop on bifurcation and degradation in geomaterials dedicated to Hans Muhlhaus. Limassol, Cyprus, 21-25 May 2017, p. 249-257.DOI:10.1007/978-3-319-56397-8_32

16. Ucgul, M., Fielke, J.M., Saunders, C. (2015). Three-dimensional discrete element modelling (DEM) of tillage: Accounting for soil cohesion and adhesion. Biosystems Engineering,vol. 169, 298306.DOI:10.1016/j.biosystemseng.2014.11.006

17. Ucgul, M., Saunders, C., Fielke, J.M. (2017). Discrete element modelling of top soil burial using a full scalemouldboard plough under field conditions. Biosystems Engineering,vol. 160, 140-153.DOI:10.1016/j. biosystemseng.2016.12.002

18. Shahgholi, G., Kanyawi, N., Kalantari, D.(2015). Modeling the effects of narrow blade geometry on soil failure draught and vertical forces using discrete element method. Yuzuncu Yil University Journal of Agricultural Sciences,vol. 29, 24-33.DOI:10.29133/ yyutbd. 429950

19. Fleischmann, J., Serban, R., Negrut, D. (2016). On the importance of displacement history in softbody contact models. Journal of Computational and Nonlinear Dynamics,vol. 11, no.4, 044502. DOI:10.1115/1.4031197

20. Milkevych, V., Munkholm, L.J., Chenc, Y., Nyord, T. (2018). Modelling approach for soil displacement in tillage using discrete element method. Soil \& Tillage Research,vol. 183, 60-71.DOI:10.1016/j. still.2018.05.017 
21. Sun, J., Wang, Y., Ma, Y., Tong, J., Zhang, Z. (2018). DEM simulation of bionic subsoilers (tillage depth $>40 \mathrm{~cm}$ ) with drag reduction and lower soil disturbance characteristics. Advances in Engineering Softwate,vol. 119, 30-37.DOI:10.1016/j.advengsoft.2018.02.001

22. Tamas, K.(2018). The role of bond and damping in the discrete element model of soil-sweep interaction. Biosystems Engineering,vol. 169, 57-70. DOI:10.1016/j.biosystemseng.2018.02.001

23. Ucgul, M., Saunders, C., Fielke, J.M.(2018). Comparison of the discrete element and finite element methods to model the interaction of soil and tool cutting edge. Biosystems Engineering,vol. 169, 199208.DOI:10.1016/j.biosystemseng.2018.03.003

24. Barr, J.B., Ucgul, M., Desbiolles, J.M.A., Fielke, J.M. (2018). Simulating the effect of rake angle on narrow opener performance with the discrete element method. Biosystems Engineering,vol. 171, 1-15. DOI:10.1016/j.biosystemseng.2018.04.013

25. Zeng, Z., Chen, Y. (2019). Simulation of straw movement by discrete element modelling of straw-sweepsoil interaction. Biosystems Engineering,vol. 180, 25-35.DOI:10.1016/j.biosystemseng.2019.01.009

26. Mudarisov, S.G., Rakhimov, Z.S., lamaletdinov, M.M., Farkhutdinov, I.M. (2010). Estimation of technological process of soil tillage based on contonuous media dynamics equation. Achievements of Science and Technology of Agribusiness,vol. 1, 63-65. (in Russian)

27. Mudarisov, S.G., Gabitov, I.I., Lobachevsky, Y.P., Mazitov, N.K., Rakhimov, R.S., Khamaletdinov, R.R., Rakhimov, I.R., Farkhutdinov, I.M., Mukhametdinov, A.M., Gareev, R.T.(2019). Modeling the technological process of tillage. Soil \& Tillage Research,vol. 190, 70-77.DOI:10.1016/j.still.2018.12.004
28. Bravo, E.L., Tijskens, E., Suarez, M.H., Cueto, O.G., Ramon, H. (2014). Prediction model for non-inversion soil tillage implemented on discrete element method. Computers and Electronics in Agriculture, vol. 106, 120-127.DOI:10.1016/j.compag.2014.05.007

29. Zeng, Z., Chen, Y., Zhang, X.(2017). Modelling the interaction of a deep tillage tool with heterogeneous soil. Computers and Electronics in Agriculture,vol. 143, 130-138.DOI:10.1016/j.compag.2017.10.005

30. Tekeste, M.Z., Balvanz, L.R., Hatfield, J.L., Ghorbani, S. (2019). Discrete element modeling of cultivator sweep-to-soil interaction: Worn and hardened edges effects on soil-tool forces and soil flow. Journal of Terramechanics,vol. 82, 1-11.DOI:10.1016/j.jterra.2018.11.001

31. Karmakar, S., Ashrafizadeh, S.R., Kushwaha, R.L.(2009). Experimental validation of computational fluid dynamics modeling for narrow tillage tool draft. Journal of Terramechanics,vol. 46, 277-283. DOI:10.1016/j.jterra.2009.06.001

32. Ani, O.A., Uzoejinwa, B.B., Ezeama, A.O., Onwualu, A.P., Ugwu, S.N., Ohagwu, C.J. (2018). Overview of soil-machine interaction studies in soil bins. Soil \& Tillage Research,vol. 175, 13-27.DOI:10.1016/j. still.2017.08.002 